\title{
DIFERENTES INDUTORES PARA PRODUÇÃO DE LIPASE DE Cryptococcus curvatus NRRL Y-1511 EM MEIO CONTENDO GLICERINA ORIUNDA DO BIODIESEL
}

\author{
B.L. LADEIRA ${ }^{1}$ e C.A.V.BURKERT ${ }^{1}$ \\ ${ }^{1}$ Universidade Federal do Rio Grande. Escola de Química de Alimentos \\ E-mail para contato: profbrunoladeira@gmail.com
}

\begin{abstract}
RESUMO - Este trabalho propõe o uso da glicerina residual como principal fonte de carbono na produção de lipase de Cryptococcus curvatus NRRL Y-1511, testando quatro diferentes indutores (Tween 80, Tween 20, óleo de soja e borra de óleo de soja) com o objetivo de aumentar a produção de lipase. Foram avaliados parâmetros relacionados ao crescimento celular e à produção da enzima e verificou-se que os indutores diferiram entre si, obtendo-se maior valor de atividade lipolítica $\left(1,57 \pm 0,02 \mathrm{U}_{\mathrm{mL}} \mathrm{mL}^{-1}\right)$ e produtividade enzimática $\left(0,0657 \pm 0,0009 \mathrm{U} \cdot \mathrm{mL}^{-1} \cdot \mathrm{L}^{-1}\right)$ com o uso de Tween 80 , enquanto que a borra de óleo de soja apresentou maiores valores referentes ao crescimento celular (biomassa máxima de $12,95 \pm 0,04 \mathrm{~g} . \mathrm{L}^{-1}$ e $\mu_{\max }$ de $0,632 \pm 0,011 \mathrm{~h}^{-1}$ ). Porém maior valor de biomassa máxima $\left(20,96 \pm 0,11\right.$ g.L . $\left.^{-1}\right)$ foi obtido na ausência de indutores no meio de cultivo.
\end{abstract}

\section{INTRODUÇÃO}

Os biocombustíveis, como o biodiesel, representam uma alternativa renovável e ambientalmente segura aos combustíveis fósseis, visto que além de ajudar a diminuir as emissões de gases de efeito estufa, que gera um grande impacto negativo sobre a biodiversidade, é ao mesmo tempo uma fonte estratégica de energia renovável para substituir o óleo diesel e derivados de petróleo (Accarini, 2009).

Entretanto, um dos grandes problemas da cadeia produtiva do biodiesel é a incapacidade do mercado de absorver toda a glicerina gerada na sua produção, resultando em um excedente desse subproduto que encarece o processo de produção do biodiesel e também causa impacto ambiental (Bilgen et al., 2008; Silva et al., 2009).

Desta forma, muitas pesquisas são conduzidas em busca de novas aplicações para o excesso de glicerina bruta. Uma alternativa promissora que pode agregar valor à cadeia produtiva do biodiesel é a conversão microbiana da glicerina em produtos de maior valor agregado (Hasan et al., 2006).

Nesse contexto, as leveduras são atraentes para a indústria biotecnológica, pois possuem um sistema metabólico capaz de utilizar a glicerina bruta como fonte de carbono e energia em processos de cultivos microbianos. Logo, é importante um estudo que permita avaliar o 
potencial biotecnológico desses micro-organismos para a obtenção de biomoléculas com propriedades importantes (Rivaldi et al., 2007) .

Esse trabalho vem contribuir para minimizar os efeitos negativos da produção do biodiesel e agregar valor à glicerina bruta, por meio do seu uso como fonte de carbono pela levedura Cryptococcus curvatus NRRL Y-1511 para a produção de lipase extracelular. Buscase ainda aumentar a produção da enzima, testando quatro diferentes indutores (Tween 80, Tween 20, óleo de soja e borra de óleo de soja).

\section{MATERIAL E MÉTODOS}

O cultivo da levedura Cryptococcus curvatus NRRL Y-1511 foi realizado em frascos Erlenmeyer de $500 \mathrm{~mL}$ contendo $200 \mathrm{~mL}$ de meio proposto por Lee et al.(2007), com a seguinte composição: 12 g.. -1 $^{-1}$ de glicerina residual, 3 g.L L $^{-1}$ de extrato de malte, 3 g.L ${ }^{-1}$ de extrato de levedura e 5 g. $\mathrm{L}^{-1}$ de peptona, inoculados com suspensão de leveduras previamente preparada com meio de mesma composição, de forma a atingir concentração celular de $1 \times 10^{7}$ células. $\mathrm{mL}^{-1}$.

Foi realizado também em paralelo outros cultivos com o mesmo meio de cultura onde foram testados quatro diferentes indutores (Tween 80, Tween 20, óleo de soja e borra de óleo de soja), na concentração de 10 g.L $\mathrm{L}^{-1}$, com o intuito de aumentar a produção de lipase. A quantidade de glicerina bruta adicionada ao meio de cultivo levou em conta sua composição (83\% de glicerol) a fim de resultar na concentração de glicerol desejada nos meios de cultivo.

Os frascos foram mantidos em incubadora rotatória a $30^{\circ} \mathrm{C}$ e $180 \mathrm{rpm}$ de agitação, retirando-se alíquotas ao longo do cultivo, as quais foram centrifugadas sob refrigeração $\left(7^{\circ} \mathrm{C}\right)$ a $5241 \mathrm{x}$ g por 15 min para as determinações analíticas ao longo do cultivo, no sobrenadante e sedimento. Todos os cultivos foram realizados em triplicata e os resultados foram avaliados por análise de variância e teste de Tukey a $95 \%$ de confiança $(p \leq 0,05)$.

O crescimento celular foi monitorado por medida da absorbância a $600 \mathrm{~nm}$. A concentração de biomassa foi expressa em massa seca $\left(\mathrm{g} . \mathrm{L}^{-1}\right)$, a partir de uma curva padrão de biomassa determinada para Cryptococcus curvatus NRRL Y-1511. Com os dados da biomassa foi também obtida a velocidade específica máxima de crescimento celular, em $\mathrm{h}^{-1}$. $\mathrm{O}$ $\mathrm{pH}$ ao longo dos cultivos foi medido diretamente em medidor de $\mathrm{pH}$ previamente calibrado (AOAC, 2000).

Para determinação da atividade lipolítica foi adotado o método baseado na titulação dos ácidos graxos liberados pela ação da enzima lipase, presente no caldo bruto livre de células, sobre os triacilgliceróis do óleo de oliva emulsionados em goma arábica, conforme descrito por Burkert (2003). A atividade lipolítica foi calculada através da Equação 1. Foi também determinada a produtividade enzimática através da Equação 2. 


$$
\begin{aligned}
& \text { Ativ }=\frac{\Delta V \cdot N \cdot 1000}{t . v} \\
& P R O D_{E}=\frac{A t i v_{\max }}{t_{f}}
\end{aligned}
$$

Ativ: Atividade lipolítica (U.mL $\left.{ }^{-1}\right)$;

Ativ $_{\max }$ : Atividade lipolítica máxima alcançada em cada ensaio (U.mL $\left.{ }^{-1}\right)$;

Prod $_{\mathrm{E}}$ : Produtividade enzimática $\left(\mathrm{U} \cdot \mathrm{mL}^{-1} \cdot \mathrm{h}^{-1}\right)$;

$\Delta \mathrm{V}$ : Diferença entre o volume gasto para titular a amostra e o branco $(\mathrm{mL})$;

$\mathrm{v}$ : Volume de caldo bruto livre de células $(\mathrm{mL})$;

$\mathrm{N}$ : Normalidade da solução de hidróxido de sódio $(\mathrm{N})$;

t: Tempo de reação $(\min )$;

$\mathrm{t}_{\mathrm{f}}$ : Tempo de cultivo $(\mathrm{h})$;

\section{RESULTADOS E DISCUSSÃO}

A Figura 1 apresenta o perfil de atividade lipolítica da lipase de Cryptococcus curvatus NRRL Y-1511 em meio de cultivo com e sem adição de indutor.

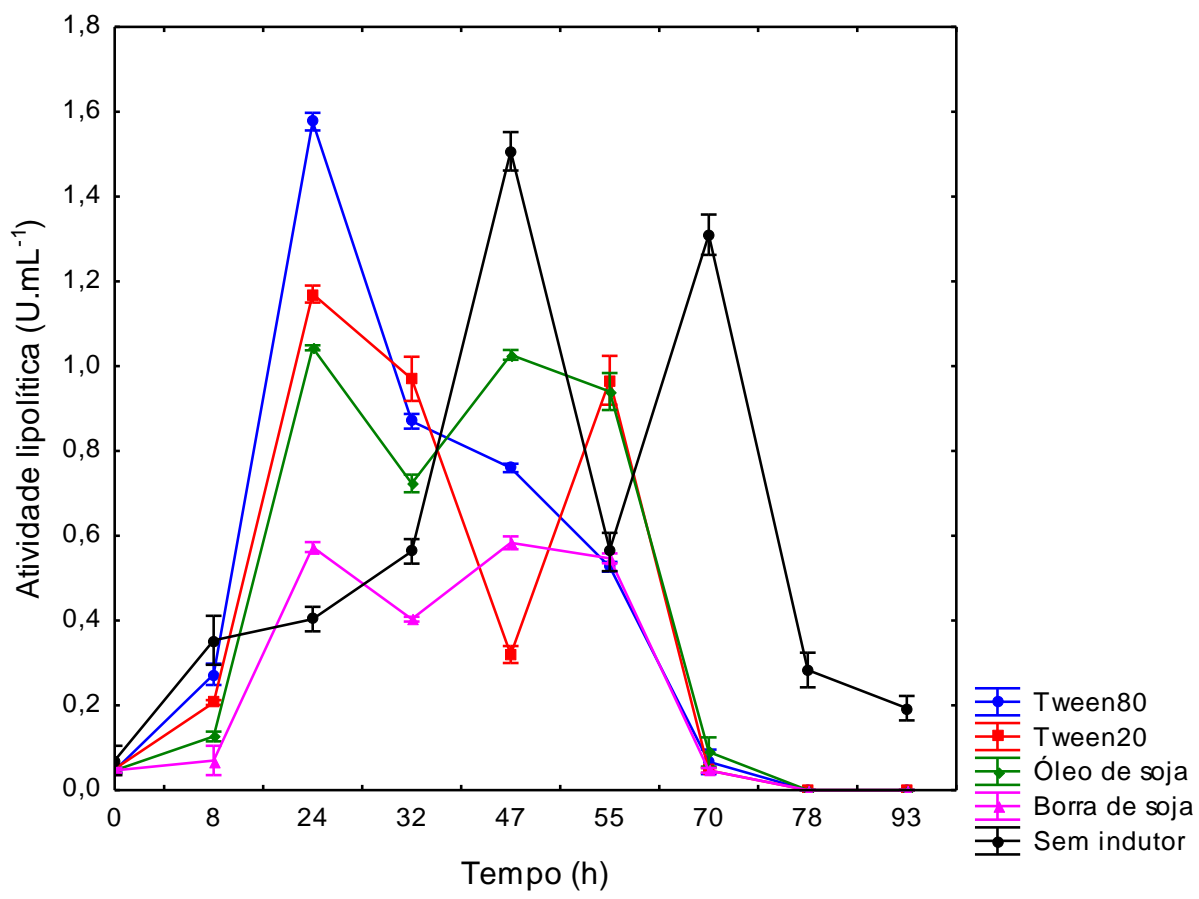

Figura 1 - Atividade lipolítica nos cultivos de Cryptococcus curvatus NRRL Y-1511 com e sem adição de indutor. 
Analisando a Figura 1, é possível verificar que com os diferentes tipos de indutores alcançou-se atividade lipolítica máxima nas primeiras $24 \mathrm{~h}$ de cultivo. Com a adição de Tween 80 obteve-se o maior valor de atividade lipolítica $\left(1,57 \mathrm{U} \cdot \mathrm{mL}^{-1}\right)$, enquanto que para os outros indutores (Tween 20, óleo de soja e borra de óleo de soja ) obteve-se respectivamente $1,17,1,04$ e 0,57 U.mL ${ }^{-1}$.

Esses resultados são interessantes uma vez que na ausência de indutor foi alcançada atividade lipolítica máxima (1,51 U.mL $\left.{ }^{-1}\right)$ em 47 h de cultivo. Sendo assim percebe-se que o uso de indutor favoreceu a produção da enzima, aumentando a produtividade.

A literatura reporta estudos com diversos indutores para a produção de lipase, tendo destaque Tween 20 e Tween 80, sendo que o uso do ultimo levou a um aumento expressivo da atividade lipolítica (Ali et al., 2010; Salihu et al.,2011; Yadav et al., 2011).

A Figura 2 apresenta o acompanhamento de $\mathrm{pH}$ ao longo dos cultivos realizados com e sem adição de indutor.



Figura 2- pH ao longo dos cultivos realizados com e sem adição de indutor.

Com relação ao pH (Figura 2), usando Tween 80 como indutor, foi observado a menor oscilação (entre 6,5 e 7,5), sendo que com óleo de soja, Tween 20 e borra de óleo de soja foi observada forte queda no pH entre $32 \mathrm{~h}$ e $47 \mathrm{~h}$ de cultivo (7,3 a 5,6; 7,1 a 5,5; e 7,4 a 5,3, respectivamente). Em contrapartida, sem indutor, a tendência é de aumento de $\mathrm{pH}$ ao longo do cultivo (de 6,7 a 8,5). 
A Figura 3 mostra o acompanhamento da biomassa da levedura Cryptococcus curvatus NRRL Y-1511 ao longo do cultivo para os ensaios com e sem adição de indutor.

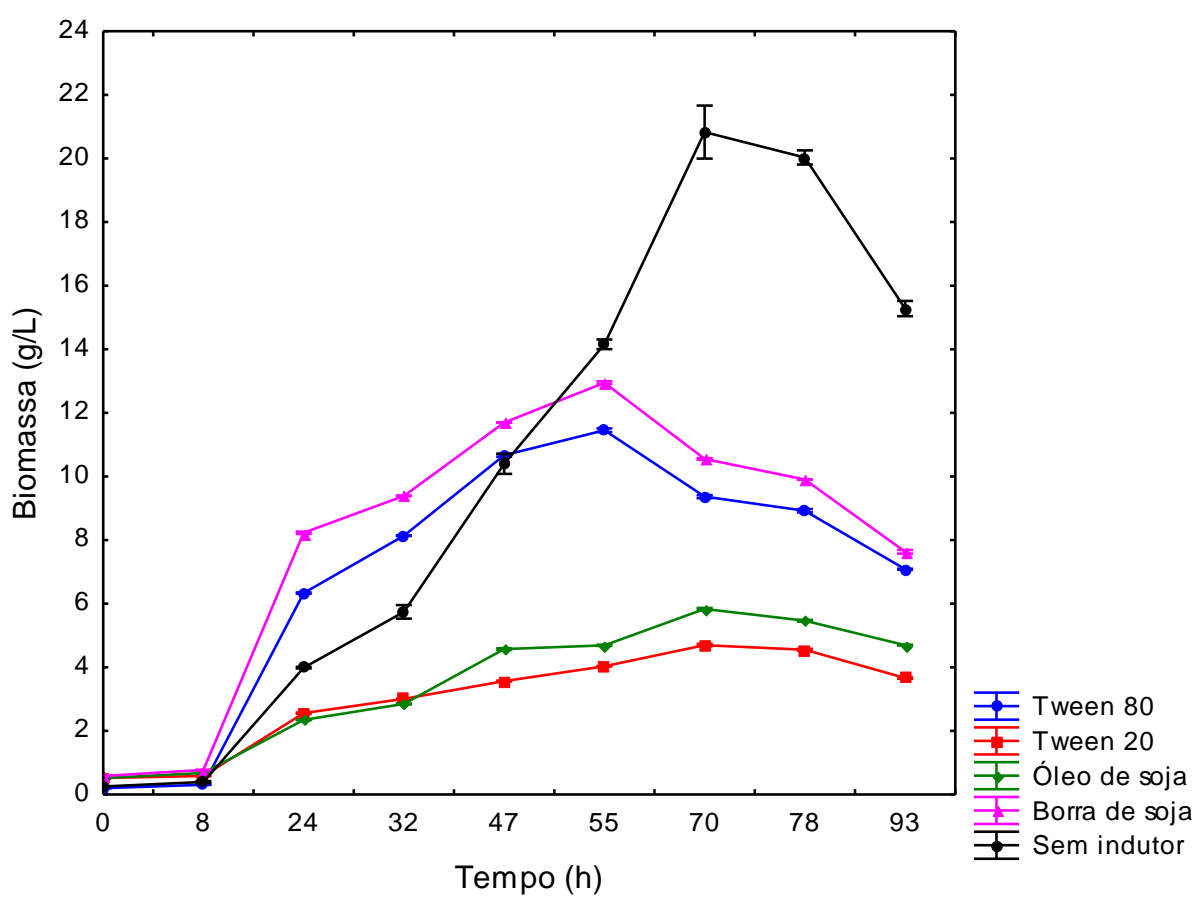

Figura 3 - Biomassa da levedura Cryptococcus curvatus NRRL Y-1511 ao longo dos cultivos realizados com e sem adição de indutor.

Analisando a Figura 3, pode ser observado que o uso de indutores ocasionou um decréscimo na biomassa da levedura. Uma provável explicação para tal fato pode estar ligada ao aumento da concentração de carbono no meio de cultivo pelos indutores, que gera uma alteração na relação $\mathrm{C} / \mathrm{N}$ que pode não ser favorável ao crescimento celular (Papanikolaou et al., 2009).

A Tabela 1 apresenta a média \pm desvio padrão para os parâmetros de cultivo relacionados ao crescimento celular da levedura $\left(X_{\max }\right.$ e $\left.\mu_{\max }\right)$ e à produção de lipase (Ativ $v_{\max }$. e $\operatorname{Prod}_{\mathrm{E}}$ ). De acordo com a Tabela 1, comparando-se os valores dos parâmetros relacionados ao crescimento celular e à produção da enzima, observa-se, a um nível de significância de $95 \%(\mathrm{p} \leq 0,05)$, que os indutores diferiram entre si, e que maior valor de atividade $(1,57 \pm 0,02$ U.mL $\left.{ }^{-1}\right)$ e produtividade enzimática $\left(0,0657 \pm 0,0009 \mathrm{U} \cdot \mathrm{mL}^{-1} \cdot \mathrm{L}^{-1}\right)$ foram obtidos com o uso de Tween 80 como indutor, enquanto que a borra de óleo de soja, quando comparada ao outros indutores, apresentou maiores valores dos parâmetros relacionados ao crescimento celular, sendo estes: $\mathrm{X}_{\max }\left(12,95 \pm 0,04 \mathrm{~g} . \mathrm{L}^{-1}\right)$ e $\mu_{\max }\left(0,632 \pm 0,011 \mathrm{~h}^{-1}\right)$. Porém, maior valor de biomassa máxima $\left(20,96 \pm 0,11 \mathrm{~g} . \mathrm{L}^{-1}\right)$ foi obtido na ausência de indutores no meio de cultivo. 
Tabela 1 - Média \pm desvio padrão para os parâmetros de cultivo relacionados ao crescimento celular e à produção de lipase

\begin{tabular}{ccccc}
\hline Indutor & $\begin{array}{c}\mathrm{X}_{\max } \\
\left(\mathrm{g} \cdot \mathrm{L}^{-1}\right)\end{array}$ & $\begin{array}{c}\mu_{\max } \\
\left(\mathrm{h}^{-1}\right)\end{array}$ & $\begin{array}{c}\text { Ativ. } \\
\left(\mathrm{U} \cdot \mathrm{mL}^{-1}\right)\end{array}$ & $\begin{array}{c}\operatorname{Prod}_{\mathrm{E}} \\
\left(\mathrm{U} \cdot \mathrm{mL}^{-1} \cdot \mathrm{h}^{-1}\right)\end{array}$ \\
\hline Sem indutor & $20,96 \pm 0,11^{\mathrm{a}}$ & $0,312 \pm 0,021^{\mathrm{b}}$ & $1,51 \pm 0,01^{\mathrm{b}}$ & $0,0320 \pm 0,0002^{\mathrm{d}}$ \\
Tween 80 & $11,45 \pm 0,06^{\mathrm{c}}$ & $0,311 \pm 0,014^{\mathrm{b}}$ & $1,57 \pm 0,02^{\mathrm{a}}$ & $0,0657 \pm 0,0009^{\mathrm{a}}$ \\
Tween 20 & $4,70 \pm 0,04^{\mathrm{e}}$ & $0,103 \pm 0,014^{\mathrm{c}}$ & $1,17 \pm 0,02^{\mathrm{c}}$ & $0,0487 \pm 0,0009^{\mathrm{b}}$ \\
& & & & \\
Óleo de soja & $5,83 \pm 0,03^{\mathrm{d}}$ & $0,104 \pm 0,010^{\mathrm{c}}$ & $1,04 \pm 0,01^{\mathrm{d}}$ & $0,0435 \pm 0,0003^{\mathrm{c}}$ \\
& & & & \\
$\begin{array}{c}\text { Borra de óleo } \\
\text { de soja }\end{array}$ & $12,95 \pm 0,04^{\mathrm{b}}$ & $0,632 \pm 0,011^{\mathrm{a}}$ & $0,57 \pm 0,01^{\mathrm{e}}$ & $0,0239 \pm 0,0005^{\mathrm{e}}$ \\
\hline
\end{tabular}

* Letras minúsculas iguais indicam que não há diferença significativa entre linhas, a 95\% de confiança (p>0,05). $\mathrm{X}_{\max }$ - Biomassa máxima; Prod $_{\mathrm{X}}$ - Produtividade em biomassa; $\mu_{\max }$ - Velocidade especifica máxima de crescimento celular; Ativ $\max _{\text {- }}$ Atividade lipolítica máxima; $\operatorname{Prod}_{\mathrm{E}}$ - Produtividade enzimática.

\section{CONCLUSÕES}

Diferentes indutores foram testados na produção de lipase por Cryptococcus curvatus NRRL Y-1511 cultivada em meio à base de glicerina residual oriunda de indústria de produção de biodiesel. O Tween $80\left(10\right.$ g.L $\left.\mathrm{L}^{-1}\right)$ exerceu efeito positivo sobre a produção da enzima, dobrando a produtividade enzimática quando comparado ao meio sem indutor, atingindo-se 1,57 U.mL ${ }^{-1}$ em $24 \mathrm{~h}$ de cultivo.

\section{REFERÊNCIAS}

ACCARINI, J.H. Competitivo e sustentável. Revista BiodieselBr, v. 12, 2009.

ALI, S.; RAFI, H.; UL-HAQ, I. Production of a extracellular lipase from Candida lipolytica and parameter significance analysis by Plackett- Burman design. Eng. Life Sci., v.10, n. 5, p. 465-473, 2010.

AOAC - ASSOCIATION OF OFFICIAL ANALYTICAL CHEMISTS. Official Methods of Analysis. $17^{\text {th }}$ edition. Washington, D.C., CD-ROM, 2000.

BILGEN, S.; KELES, S.; KAYGUSUZ, A.; SARI, A.; KAYGUSUZ, K. Global warming and renewable energy sources for sustainable development: A case study in Turkey. Renewable Sustainable Energy Rev., v. 12, p. 372-396, 2008. 
BURKERT, J.F.M. Otimização das condições de produção da lipase por Geotrichum candidum NRRL-Y552. Tese (Doutorado em Engenharia de Alimentos). Universidade Estadual de Campinas-UNICAMP, Campinas, 2003.

HASAN, F.; SHAH, A.A.; HAMEED, A. Industrial applications of microbial lipases. Enzyme and Microb. Technol., v. 39, p. 235 - 251, 2006.

LEE, G-H; BAE, J-H.; SUH, M-J.; KIM, I-H.; HOU, C.T.; KIM, H-R. New finding and optimal production of a novel extracellular alkaline lipase from Yarrowia lipolytica NRRL Y-2178. J. Microbiol. Biotechnol., v. 17, p. 1054-1057, 2007.

PAPANIKOLAU, S.; AGGELIS, G. Biotechnological valorization of biodiesel derived glycerol waste through production of single cell oil and citric by Yarrowia lipolytica. Lipid Technol., v. 21, n. 4, p. 83-87, 2009.

RIVALDI, J.D.; SARROUH B.F.; SILVIO, R.F; SILVA, S. Glicerol de biodiesel. Biotecnologia Ciência \& Desenvolvimento, v. 37, p. 44-52, 2007.

SALIHU, A.; ALAM, Z.M.; ABDULKARIM, I.M.; SALLEH, M.H. Optimization of lipase production by Candida cylindracea in palm oil mill effluent based medium using statistical experimental design. J. Mol. Catal. B: Enzym., v. 69, p. 66-73, 2011.

SILVA, G.P.; MACK, M.; CONTIERO, J. Glycerol: A promising and abundant carbon source for industrial microbiology. Biotechnol. Adv., v. 27, p. 30-39, 2009.

YADAV, K.N.S.; ADSUL, M.G.; BASTAWDE, K.B.; JADHAV, D.D.; THULASIRAM, H.V.; GOKHALE, D.V. Differential induction, purification and characterization of cold active lipase from Yarrowia lipolytica NCIM 3639. Bioresour. Technol., v. 102, p. 10663-10670, 2011. 